Imlay, T. L., S. Saldanha, and P. D. Taylor. 2020. The fall migratory movements of Bank Swallows, Riparia riparia: fly-and-forage migration?. Avian Conservation and Ecology 15(1):2. https://doi.org/10.5751/ACE-01463-150102

Copyright $(C) 2020$ by the author(s). Published here under license by the Resilience Alliance.

Research Paper

\title{
The fall migratory movements of Bank Swallows, Riparia riparia: fly- and-forage migration?
}

\author{
Tara L. Imlay ${ }^{1}$, Sarah Saldanha ${ }^{2}$ and Philip D. Taylor ${ }^{1}$ \\ ${ }^{1}$ Department of Biology, Acadia University, Wolfville, NS, Canada, ${ }^{2}$ Biology Department, Dalhousie University, Halifax, NS, \\ Canada
}

\begin{abstract}
Seasonal migration is an important part of the annual cycle for migratory birds, and it is associated with large time and energy expenditures. One migration strategy used by many raptors and aerial foragers is fly-and-forage migration. Fly-and-forage migrants combine migratory flights with foraging to maximize travel speeds. We examine the fall migratory movements of a declining population of Bank Swallows Riparia riparia that breed in Atlantic Canada, and winter between northern Argentina and southern Brazil. We tagged breeding adults with small VHF transmitters in 2014, 2015, and 2018, and tracked them with the Motus Wildlife Tracking System. For each individual we determined a departure date (last detection at the breeding colony), a departure bearing, the broad-scale migratory pathway (east or west of the Adirondack Mountains), and the pace of the migratory journey. Bank Swallows departed from their breeding colonies throughout July and August and most individuals departed in a southwest to westerly direction, consistent with their subsequent migratory pathway along the Atlantic Coast. The pace of the migratory journey was slower than that observed for other migratory passerines, suggesting individuals used stopover sites during migration and/or foraged while migrating. Travel speeds were also slower for female, compared to male Bank Swallows, possibly because of sex-related differences in refueling and/or carry-over effects from the breeding season. Collectively, the results suggest that Bank Swallows use a fly-and-forage migration strategy, and fall migration movements are consistent with an energy-limiting strategy.
\end{abstract}

\section{Déplacements migratoires automnaux des Hirondelles de rivage, Riparia riparia : migration combinant vol et alimentation}

RÉSUMÉ. Les migrations saisonnières constituent une grande part du cycle annuel chez les oiseaux migrateurs, et elles sont associées à des demandes temporelle et énergétique importantes. La migration combinant le vol et l'alimentation est une stratégie de migration utilisée par de nombreux oiseaux de proie et insectivores aériens. Dans cette stratégie de migration, les vols migratoires alternent avec ceux pour s'alimenter afin de maximiser la vitesse de déplacement. Nous avons examiné les déplacements migratoires automnaux d'une population d'Hirondelles de rivage Riparia riparia en diminution, qui niche dans le Canada Atlantique et hiverne entre le nord de l'Argentine et le sud du Brésil. Nous avons marqué des adultes nicheurs au moyen de petits émetteurs VHF en 2014, 2015 et 2018, et les avons suivis à l'aide du système de surveillance de la faune Motus. Nous avons déterminé la date de départ (dernière détection à la colonie de nidification), l'azimut pris, le trajet migratoire général (est ou ouest des Adirondacks) et la vitesse de migration de chaque individu. Les hirondelles ont quitté leur colonie de nidification en juillet et août et la plupart des individus ont pris un cap sud-ouest à ouest, conséquent avec leur trajectoire de migration subséquente le long de la côte atlantique. Le rythme migratoire était plus lent que celui d'autres passereaux migratoires, laissant croire que les individus utilisaient des haltes durant la migration et/ou s'alimentaient en vol tout en migrant. Les vitesses de déplacement étaient aussi plus lentes chez les femelles, comparativement à celles des mâles, peutêtre en raison de différences liées au sexe dans la façon de refaire ses réserves et/ou d'effets reportés de la saison de nidification. Dans l'ensemble, nos résultats indiquent que les Hirondelles de rivage utilisent une stratégie de migration combinant le vol et l'alimentation, et leurs déplacements migratoires automnaux correspondent à une stratégie limitant les dépenses énergétiques.

Key Words: automated telemetry; fly-and-forage; optimal migration; postbreeding; Sand Martin

\section{INTRODUCTION}

Throughout the year, many animals undertake migratory movements between their summer breeding and winter foraging areas. These movements are driven by multiple factors, including a need to reduce competition during specific stages of the annual cycle, exploit seasonally suitable habitats, and/or maintain fidelity to breeding sites (reviewed in Alerstam and Hedenström 1998, Winger et al. 2019). During migration animals experience significant constraints on the amount of time and energy expended (Alerstam and Hedenström 1998). To date, much research has focused on optimal migration theory to provide a framework for understanding the strategies that animals use to reduce the cost of migration and increase fitness (Hedenström and Alerstam 1997, Alerstam and Hedenström 1998). The two most commonly considered migration strategies are those that minimize either the time or energy spent during migration. Timeminimizing migrants reduce the total migration time by acquiring large fuel loads through long stopovers at a few sites and

Address of Correspondent: Tara L. Imlay, Canadian Wildlife Service, Environment and Climate Change Canada, 5421 Robertson Rd., Delta, BC, Canada, V4K 3N2, tara.imlay@canada.ca 
undertaking longer, rapid, and direct movements, possibly across large areas of unsuitable habitat that may otherwise act as barriers (Alerstam and Hedenström 1998). In contrast, energyminimizing migrants reduce the total energy spent during migration and as such, the amount of fuel carried (Hedenström and Alerstam 1997). These migrants undertake shorter, slower movements, but use more stopover sites for shorter periods of time (Alerstam and Hedenström 1998), and typically, have longer and more circuitous migration paths (Hedenström and Alerstam 1997). In reality, these extremes exist along a continuum, and species may use aspects of both time and energy minimizing strategies, depending on factors such as sex, migration distance, and season (Farmer and Wiens 1999, Warnock et al. 2004, Miller et al. 2016).

A fly-and-forage migration strategy can be used by species that also employ time or energy minimizing strategies (Alerstam 2011). While undertaking migratory flights, fly-and-forage migrants locate suitable prey midflight that they either consume on the ground (e.g., Osprey Pandion haliaetus, Strandberg and Alerstam 2007; Eurasian Hobbies Falco subbuteo, Strandberg et al. 2009; American Crow Corvus brachyrhynchos, Ward and Raim 2011) or on the wing (e.g., Common Swift Apus apus, Åkesson et al. 2012; Nathusius's bat Pipistrellus nathusii, Šuba et al. 2012). The latter group (aerial foragers) primarily consume flying insects. This strategy reduces the need to locate suitable stopover sites because individuals refuel continually throughout their migration. In birds, a fly-and-forage strategy is more common among diurnal migrants (Strandberg and Alerstam 2007, Alerstam 2009).

Our ability to categorize the migration strategies of smaller bird species, and determine how these strategies vary within a species, is constrained by our ability to track individuals through time. At present, the available tracking devices include geolocators, archival GPS tags, and radio-telemetry all of which have strengths and weaknesses. The former two are limited by the return rates of individuals equipped with the devices, which is low in some highly aerial species (Costantini and Møller 2013, Morganti et al. 2018), and, for geolocators, the scale $( \pm 200 \mathrm{~km})$ at which movements can be tracked does not provide sufficient information about departure bearings, stopover duration, and travel speeds, all of which are important for assessing migratory strategies. Automated radio-telemetry, e.g., the Motus Wildlife Tracking System (Taylor et al. 2017) can alleviate some of these issues by providing insight into the movements of tagged birds at a finer scale $( \pm 15 \mathrm{~km})$, allowing for more accurate estimates of bearings, stopover duration, and travel speeds where automated receiving stations are available.

Swallow (Family Hirundinidae) migration is relatively poorly studied. Indeed, the only measures of migration speeds that we are aware of were based on the recapture of two banded Barn Swallows Hirundo rustica that travelled 320 and $433 \mathrm{~km} /$ day (Turner 2004). Because these aerial foragers migrate during the day (Imlay and Taylor, in press), it seems likely that they employ a fly-and-forage migratory strategy. But it is not clear whether foraging occurs at specific sites or continually during migratory flights. A fly-and-forage migration strategy may have added benefits for these species because it would reduce the need to carry large fuel loads that can result in disproportionately lower travel speeds, particularly in species with such streamlined body plans (Alerstam and Hedenström 1998, but see Kvist et al. 2001).
We tracked the fall migratory movements of Bank Swallows Riparia riparia from several colonies in southern New Brunswick, Canada using the Motus Wildlife Tracking System. We predicted that if this species uses a fly-and-forage strategy, then migration routes would be directed toward their winter range (throughout southern Brazil to northern Argentina; Imlay et al. 2018) with slow travel speeds due to frequent stopovers.

\section{METHODS}

\section{Capture and tagging}

In June and July 2014 and 2015, we captured adult Bank Swallows (25 and 44, respectively) in tube-traps and mist-nets at three adjacent breeding colonies along the Tantramar River in New Brunswick, Canada (45.8964 ${ }^{\circ},-64.3447^{\circ}$; Fig. 1), one in 2014 and two different colonies in 2015. We attached $0.29 \mathrm{~g} \mathrm{NTQB-1-1}$ VHF nanotags from Lotek Wireless Inc., Newmarket, Ontario to these adults by gluing the tags to trimmed feathers on the bird's lower back (Raim 1978). The minimum battery life of these tags (i.e., $\sim 80 \%$ of estimated battery life) was estimated at 33 days and each tag had a burst interval of $\sim 10 \mathrm{~s}$. These tags were largely deployed during the late incubation period and given their limited battery life, we considered that many may cease transmitting before individual initiated migration.

Fig. 1. Locations of breeding colonies where Bank Swallows Riparia riparia were captured and tagged during each year of this study, and Motus Wildlife Tracking System receiving stations around breeding colonies. Detections at stations within $2 \mathrm{~km}$ of the closest breeding colony were considered to represent individuals at the breeding colony.

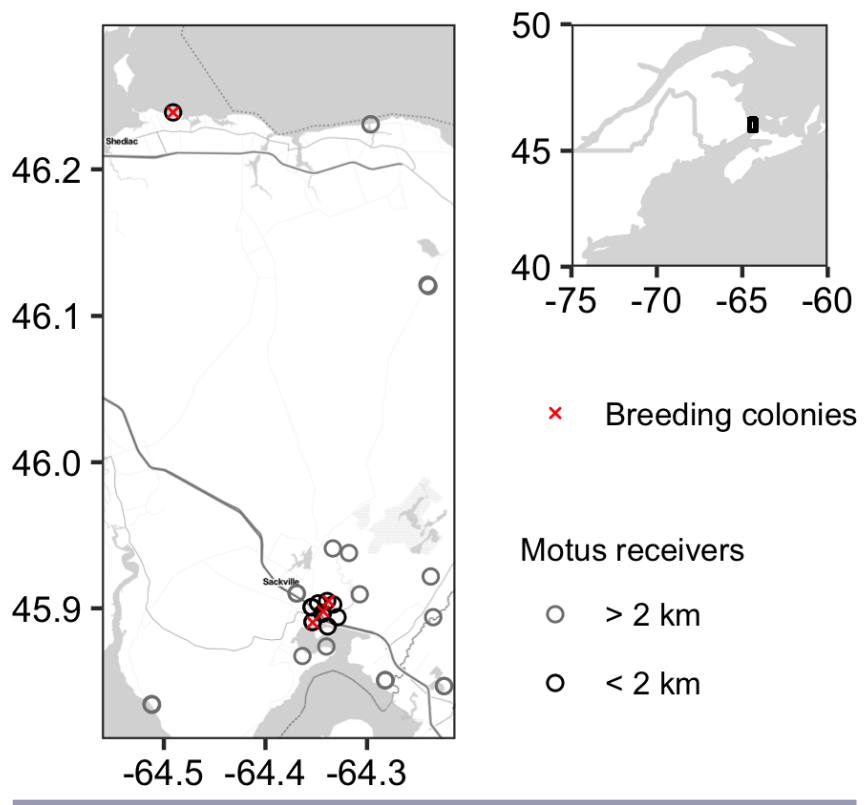

In July 2018, we captured 19 adult bank swallows in mist-nets at two breeding colonies in New Brunswick, Canada, including the same colony along the Tantramar River where individuals were tagged in 2014 and another location near Shediac $\left(46.2388^{\circ},-64.4910^{\circ}\right.$; Fig. 1$)$. We attached 0.35 g NTQB-2-2 VHF nanotags using a leg-loop harness made with an elastic thread (Rappole and Tipton 1991). The minimum battery life of these 
tags was estimated at 139 days and each tag had a burst interval of $\sim 35 \mathrm{~s}$. The specific timing during the breeding season of these deployments was unknown but thought to coincide with the nestling period.

To minimize potential effects of tagging on behavior and survival, we used tag attachment methods that are thought to result in the loss of the tag shortly after the battery has died (Barron et al. 2010, Brlík et al. 2020). In 2014 and 2015, the glue-on attachment used was estimated to last for 5-40 days (Sykes et al. 1990, Johnson et al. 1991, Bowman et al. 2002, Mong and Sandercock 2007, Diemer et al. 2014), and, in 2018, the leg-loop harness was estimated to last for $\sim 100$ days (Streby et al. 2014).

All individuals captured were also banded with a uniquely numbered Canadian Wildlife Service aluminum band. Sex was determined by the presence of a brood patch or cloacal protuberance.

\section{Automated telemetry array}

In each study year we set up a Motus receiving station with an omni-directional antenna and a SensorGnome (https://www. sensorgnome.org/) within $100 \mathrm{~m}$ of the colony (Fig. 1). Also, in 2014 and 2015 we set up additional Motus receiving stations approximately $2 \mathrm{~km}$ from the breeding colonies (see Saldanha 2016 for more details). These omni-directional antennas had an estimated range of up to $500 \mathrm{~m}$ (Taylor et al. 2017). Because individuals were often simultaneously detected at two or more of these stations, we assumed these detections indicated that individuals were at the breeding colony.

Bank Swallows were also detected at Motus receiving stations situated throughout North and Central America. These receiving stations are equipped with one or more omni-directional or Yagi antennas and either a Lotek SRX/DX receiver or SensorGnome (Taylor et al. 2017). Receiving stations with long-range antennas (e.g., 9-element Yagi) have a detection range of up to $\sim 15 \mathrm{~km}$ (Taylor et al. 2017). The placement and number of receiving stations throughout this area varied by year (Fig. A1.1); during the period of times our tags were active, there were 152 active receiving stations in 2014, 289 in 2015, and 509 in 2018. The data included in this manuscript was uploaded and processed by Motus on or before 30 April 2019.

\section{Data processing}

Using the raw detection data from the Motus Wildlife Tracking System, we removed any detections that were likely false detections and did not actually reflect the movements of tagged individuals. These false detections were often short runs, i.e., two or three detections of a tag at a receiver within a short period of time, and were outside the likely migratory range of this population, such as throughout western Canada and the western United States of America. Furthermore, false detections were not consistent with detections of the individual at other Motus receiving stations during migration. For example, one tag was detected twice (run length $=2$ ) at a receiving station in northern Ontario between multiple detections (run lengths $=2-99$ ) at two receivers within $700 \mathrm{~km}$ of one another along the Atlantic coast; we therefore determined the northern Ontario detections were false and removed them from the dataset.
Using the filtered detections, we identified the location and time the individual was at a receiver away from its breeding colony. We used the coordinates of the Motus receiving station that detected an individual as its location at that time. The error in these locations depends on many things, but mainly the type of antenna, so we crudely estimate them to be approximately half their respective maximum detection ranges $(0.25 \mathrm{~km}$ for omnidirectional antennas and $7.5 \mathrm{~km}$ for 9 element Yagi antennas). To determine a detection time for each individual, we averaged the time of the detection with highest signal strength, which is approximately when the individual was closest to the tower, from all detections within $5 \mathrm{~min}$ of one another at all of the antennas at a given receiving station (Mitchell et al. 2015, Smetzer et al. 2017).

\section{Data analysis}

\section{Timing of departure}

As in Smetzer et al. (2017), we considered the date of the last detection of an individual at the colony to be the departure date. To determine if there were differences in departure date between sexes or across years, we fit a linear mixed model with breeding colony as a random intercept. We compared single order models with all combinations of these two variables, i.e., sex, year, and sex + year, as well as the null model with only the random intercept for breeding colony.

\section{Initial migratory departure bearings}

We consider the initial migratory pathway of individuals departing from their breeding colonies as those movements that occur within seven days after the last detection at the breeding colony. To describe these pathways, we calculated the bearing between the colony and the first receiving station where individuals were detected after departure. For individuals detected at more than one receiving station during this time, we also calculated the bearing between the breeding colony and the last receiving station they were detected at within the seven day window after departure. We excluded detections at receiving stations within $\sim 15 \mathrm{~km}$ of the breeding colony because their overlapping detection ranges could result in erroneous bearings. To determine if departure bearings are oriented in a consistent direction, we conducted a Rayleigh Test of Uniformity. If the departure bearings are, collectively, oriented in a direction consistent with migration routes, then we consider this to be evidence that we capture migratory, instead of postbreeding, movements.

\section{Migratory movements}

We consider movements further than $100 \mathrm{~km}$ from the breeding colony to be indicative of broader, landscape-level migratory movements. To describe these, we mapped all detections of each individual and determined the amount of time individuals spent at specific receiving stations. Most individuals were only detected at a station on a single day for a short period of time (mean amount of time between first and last detection: $43.4 \pm 15.0 \mathrm{~min}$, median $=7.8 \mathrm{~min}$ ); these individuals were considered to have flown past the receiver, likely during active migration. When an individual was detected on two consecutive days at the same station, and the solar elevation was $<12^{\circ}$ during the evening of the first day and the morning of the second day, i.e., between dusk and dawn, then we considered that the individual likely roosted near the receiving 
station. Individuals that were detected at a single site on two or more consecutive daylight periods, were classified as stopovers.

\section{Pace of migratory movements}

To determine the pace of migratory movements, we calculated travel speeds between receiving stations by measuring the greatcircle distance using the Vincenty (1975) formula between locations and divided by the time between detections. Because Bank Swallows are diurnal migrants (Imlay and Taylor, in press) we only included daylight hours in our calculation of the time between receiving stations. Therefore, for movements that spanned two or more days, we subtracted the total time between sunset and sunrise, i.e., the duration of the night when bank swallows roost, at the latitude midway between receiving stations from the total time spent travelling between receiving stations. As with McKinnon et al. (2016), our estimates of travel speed reflect the overall migratory pace between receiving stations. For same day detections, this metric is similar to how ground speeds are measured in radar studies. For the purposes of this analysis, we removed any estimates of travel speeds between receiving stations $<20 \mathrm{~km}$ apart because these may have been the result of simultaneous or near simultaneous detections, i.e., $<5$ minutes, and as such produce erroneously high travel speeds.

To determine if the travel speeds of individuals between receiving stations was consistent with migratory flights, i.e., no stopovers between most detections, we used a generalized linear mixed effects model with a gamma distribution and a logarithmic link function to examine the relationship between travel speed and time between detections (centered and scaled). This model included individual ID as a random intercept. We also considered that this relationship could vary with sex and whether consecutive detections were on the same or different days; we refer to the later variable as "S/D day." Therefore, we added all possible combinations of those covariates, i.e., sex, S/D day, and sex + S/ $\mathrm{D}$ day, to the base model, and included a model with just the random intercept.

For model selection, i.e., departure date and travel speeds, we identified the top models with a cumulative AIC weight $\left(\mathrm{w}_{\mathrm{i}}\right)$ of at least 0.90 , and used a conditional model averaging approach, i.e., coefficients are only averaged across models where they are present (Table 1). If the top models included a variable where confidence interval spanned zero, then we simply state that the variable was important, but we could not determine the direction of the relationship. We assessed all models for their fit by examining residual plots. All analyses were conducted in $\mathrm{R}$ version 3.5.1 (R Core Team 2018), with the CircStats, geosphere (Hijmans 2018), lme4 (Bates et al. 2015), lmerTest (Kuznetsova et al. 2017), motus (Brzustowski and Lepage 2018), and MuMIn (Barton 2016) packages.

\section{RESULTS}

\section{Timing of departure}

Bank Swallows left their breeding sites between 3 July and 17 August (Fig. 2). Although year and sex were included in top models (Table 2), we lacked sufficient data to determine whether departure dates were earlier or later in 2015 and 2018 compared to $2014\left(\beta_{2015}=7.02,95 \% \mathrm{CI}=-9.67,23.74\right.$ and $\beta_{2018}=2.92,95 \%$ $C I=-14.06,19.90$, respectively $)$ or between the sexes $\left(\beta_{m}=-0.55\right.$, $95 \% \mathrm{CI}=-4.68,3.58)$.
Table 1. Model selection table for the relationships between Bank Swallow Riparia riparia (A) departure dates and sex and year, and (B) pace of postdeparture movements and the daylight hours between detections, sex, and S/D day. A conditional model averaging approach across the top models with a cumulative $\mathrm{w}_{\mathrm{i}}$ of at least 0.90 was used to arrive at the final model coefficients.

\begin{tabular}{lcccc}
\hline \hline Model $^{\dagger}$ & $\mathrm{K}$ & $\Delta \mathrm{AIC}^{*}$ & $\mathrm{w}_{\mathrm{i}}$ & $\log$ Lik \\
\hline A) Departure date & & & & \\
sex + year + BC & 6 & 0.00 & 0.61 & -275.75 \\
year + BC & 5 & 1.01 & 0.37 & -277.43 \\
sex + BC & 4 & 7.52 & 0.01 & -281.83 \\
$\mathrm{BC}$ & 3 & 8.68 & 0.01 & -283.52 \\
$\mathrm{~B})$ Pace of movements & & & & \\
time + sex + S/D day + ID & 6 & 0.00 & 0.72 & -140.21 \\
time + sex + ID & 5 & 1.89 & 0.28 & -142.36 \\
time + S/D day + ID & 5 & 10.40 & 0.00 & -146.61 \\
time + ID & 4 & 10.71 & 0.00 & -147.94 \\
ID $^{\mid}$ & 3 & 329.40 & 0.00 & -161.49 \\
\hline
\end{tabular}

Abbreviations: $\mathrm{BC}=$ random intercept for breeding colony, days = days prior to departure, status $=$ breeding or postbreeding, time $=$ daylight hours between detections, S/D day = whether consecutive detections occurred on the same or different days, ID = random intercept for individual ID.

${ }^{\ddagger} \mathrm{AIC} c$ for the top models were 564.68 and 291.35 , respectively.

${ }^{\S}$ Models were included in model averaging.

Intercept only model.

Fig. 2. The timing of departure from breeding sites in the fall for Bank Swallows Riparia riparia by year. The bar indicates the mean departure date for each year.

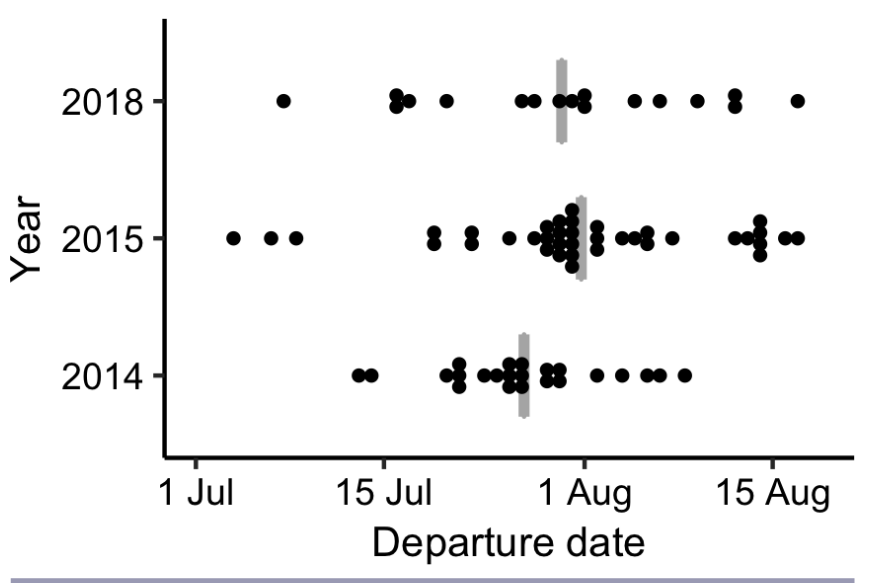

\section{Departure bearing}

After departing from their breeding colonies, most individuals detected $>100 \mathrm{~km}$ away within 7 days $(21 / 30 ; 70.0 \%)$ had moved southwest or west (Fig. 3). Moreover, six of the nine (66.7\%) that initially departed in a different direction (north, east, or south) were ultimately oriented in a southwest to westerly direction by the time of their last detection during that seven-day window. Departure bearings for each of the three groups were significantly oriented in a consistent direction $\left(_{\text {first }}=0.60, p=0.002 ;_{\text {last }}=0.91\right.$, $\mathrm{p}<0.001 ;_{\text {only }}=0.87, \mathrm{p}<0.001$ ). 
Fig. 3. Bearings and distance between the breeding colony and the first Motus receiving station where Bank Swallows Riparia riparia were detected after departing from their breeding colonies. North is indicated by $0^{\circ}$.

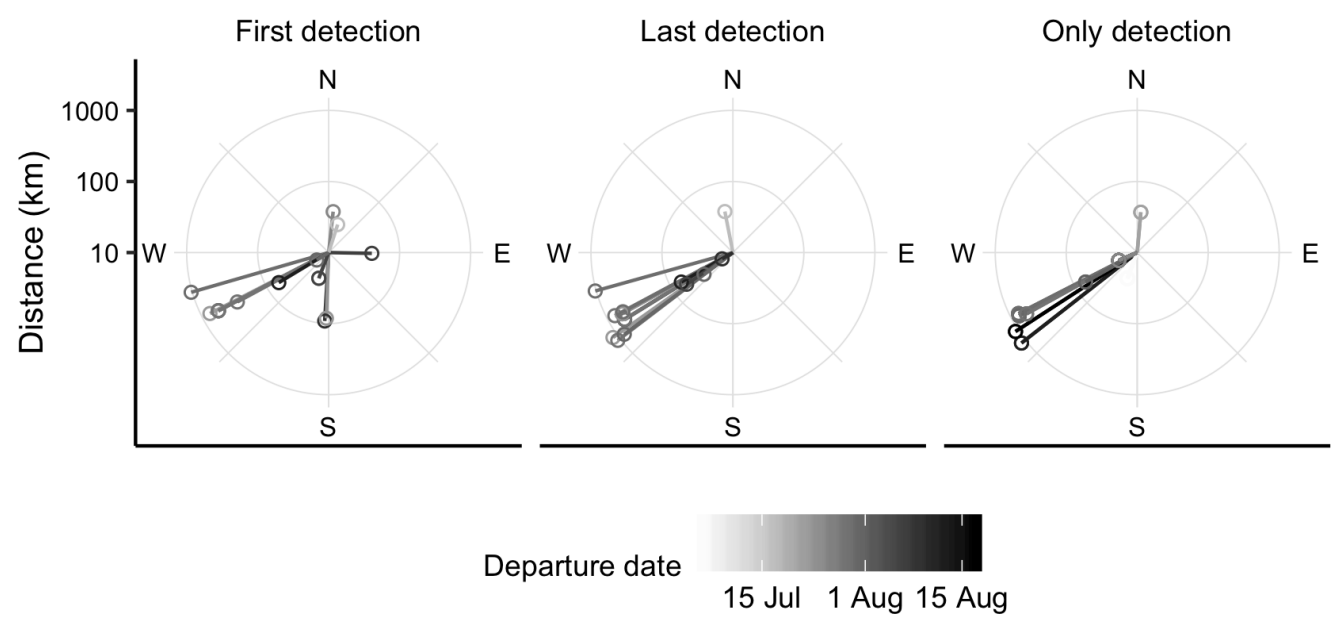

Table 2. The number of tagged Bank Swallows Riparia riparia included in each analysis.

\begin{tabular}{lcccc}
\hline \hline & 2014 & 2015 & 2018 & Total \\
\hline \# tagged & 25 & 44 & 19 & 88 \\
\# with usable data $^{\dagger}$ & 23 & 38 & 17 & 78 \\
Departure date & 23 & 38 & 17 & 78 \\
Departure bearing & 9 & 13 & 8 & 30 \\
Postdeparture movements & 3 & 13 & 9 & 25 \\
Pace of postdeparture movements & 6 & 13 & 11 & 30 \\
\hline
\end{tabular}

${ }^{\dagger}$ We excluded three individuals (one in 2015 and two in 2018) that either died, lost their tag, or their tag failed shortly after deployment, and six individuals (one in 2014 and five in 2015) where the individuals remained at the colony beyond the expected battery life of their tag (i.e., 33 days).

\section{Postdeparture movements}

After departing from their breeding colonies, the early migratory movements of most Bank Swallows $(21 / 25 ; 84.0 \%)$ were along or slightly inland from the Atlantic coast in northeastern North America, including detections in southeastern New Brunswick and through eastern parts of Maine, New Hampshire, Massachusetts, Rhode Island, New York, New Jersey, and Delaware (Fig. 4). The remaining four individuals made movements that were not, at least initially, consistent with this coastal migratory pathway (Fig. A1.2). Three individuals initially travelled east or south into Nova Scotia. One was detected along the northern shore before returning to New Brunswick and being detected at three receiving stations along the Atlantic Coast in Maine, Massachusetts, and then southeastern Pennsylvania. The other two were detected along the shore of the Minas Basin. One of these individuals was later detected at four receiving stations along the Atlantic coast in New Hampshire and then Massachusetts, while the other individual returned to eastern New Brunswick before moving west to eastern Ontario, northwestern
Fig. 4. Movements of Bank Swallows Riparia riparia after departing from their breeding colonies (A), as well as, the relationships between postdeparture detection latitude (B) and longitude $(\mathrm{C})$ in relation to the time of year.

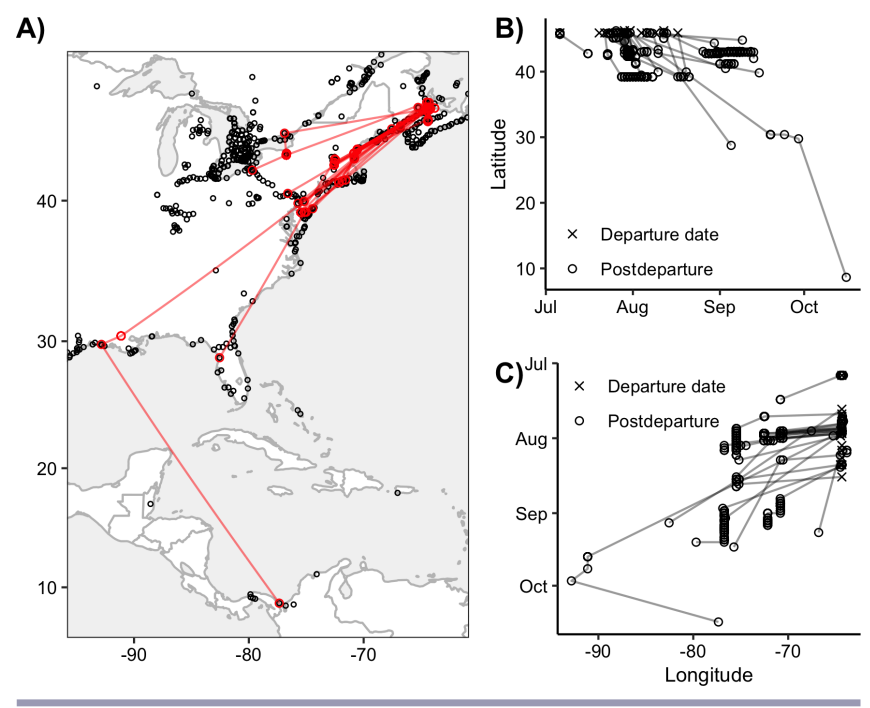

New York, and northwestern Pennsylvania. A fourth individual travelled west and was detected in northwestern New York.

Two individuals were detected south of $39^{\circ} \mathrm{N}$ (Fig. 4). The first was detected at a receiving station in eastern New Jersey before being detected along the Gulf coast of Florida on 5 September 2019. The second was not detected after leaving New Brunswick until Louisiana when it was first detected on 19 September 2019. The lack of detections between these locations makes it difficult to determine this individual's fall migratory movements through northeastern North America. However, given the high density of receiving stations along the Atlantic coast, it seems likely this individual used an inland route. This individual was also detected again in northwestern Colombia on 16 October 2019, suggesting 
that it either circumnavigated the Gulf of Mexico, or crossed from U.S. states along the northern periphery of the Gulf of Mexico to the Yucatan Peninsula, Mexico and then continued further south.

Depending on their departure date, Bank Swallows were detected migrating through the northeastern USA in July through September (Fig. 4). Like we observed for their departure bearing above, the movements of Bank Swallows throughout the northeastern USA continued to follow a southwest direction.

Finally, 97/112 $(86.6 \%)$ detections were considered fly-bys, indicating active migration. The remaining 15 detections were at receiving stations for two or more days, indicating a stopover. This included three $(2.7 \%)$ incidents where Bank Swallows likely roosted near the receiving station, and $12(10.7 \%)$ stopovers with a mean duration of $5.2 \pm 1.2$ days.

\section{Pace of postdeparture movements}

For same day detections, the mean travel speeds for female and male Bank Swallows were $5.4 \pm 1.0 \mathrm{~m} / \mathrm{s}(\mathrm{n}=13)$ and $6.9 \pm 0.8 \mathrm{~m} /$ $\mathrm{s}(\mathrm{n}=8)$, respectively. For these detections, the mean distance between receiving stations was $69.9 \pm 21.1 \mathrm{~km}$ and $32.9 \pm 5.4 \mathrm{~km}$, respectively.

The pace of Bank Swallow movements was highly variable (Fig. 5). However, travel speeds declined as the number of daylight hours between detections increased $(\beta=-0.60,95 \%$ CID $=-0.76,-0.43)$ and when detections occurred on different days, compared to same day detections $(\beta=-0.40,95 \%$ CI $=-0.78,-0.01)$. Travel speeds were slower for females, compared to males $\left(\beta_{\mathrm{m}}=0.68,95 \% \mathrm{CI}=0.32,1.05\right)$.

Fig. 5. Travel speeds (m/s) of female and male Bank Swallow Riparia riparia movements between receiving stations (with same and different day detections) during postdeparture movements and the time between detections.

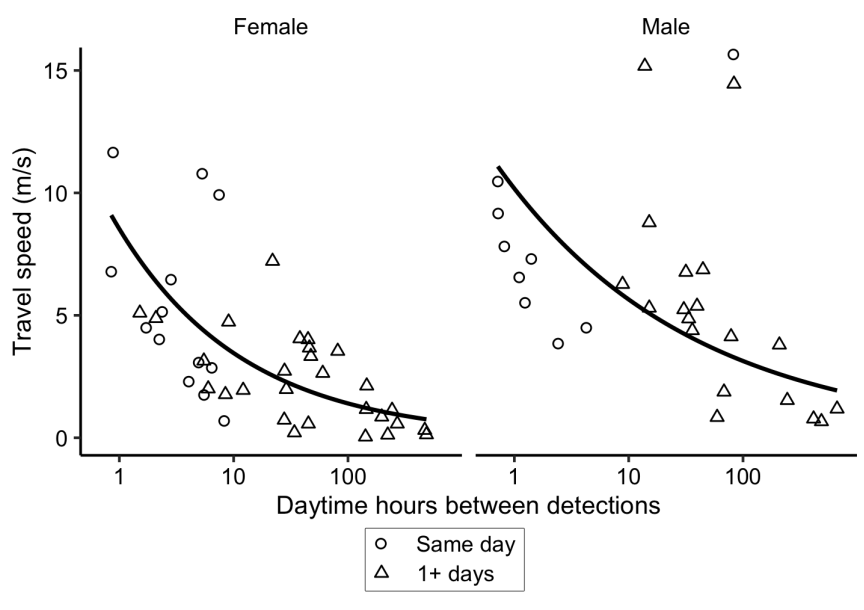

\section{DISCUSSION}

Most individuals from the northeastern population of Bank Swallows we studied departed from their breeding colonies between late July to early August. After departing, Bank Swallows travelled along a southwest to west trajectory, which they maintained through the northeastern part of their primary migratory path along the eastern seaboard of North America. During this time, the pace of movement was slower than the observed ground speeds for other migratory passerines (e.g., Nilsson et al. 2014, Mitchell et al. 2015), suggesting multiple stopovers during these flights. Males travelled faster than females.

Bank Swallows travel in straight paths during migration (Hedenström and Alerstam 1997, Miller et al. 2016). The departure bearing exhibited by most Bank Swallows suggests that after these individuals leave, they begin travelling in a direction consistent with their migratory routes with little support for broad-scale postbreeding movements, at least in the areas covered by the Motus network. This is in contrast to other passerine species tracked during fall migration in this region that have more extensive postbreeding movements throughout the northeast (e.g., Blackpoll Warbler Setophaga striata, Red-eyed Vireo Vireo olivaceus, Brown and Taylor 2015, Smetzer and King 2018).

Like a fly-and-forage migrant, the pace of migratory movements in Bank Swallows slowed with increasing time between detections, and even same-day detections suggest Bank Swallow travel speeds are slower than other migrants (e.g., Nilsson et al. 2013, Mitchell et al. 2015). Such a pattern would result from a species that is actively refueling during migration. Refueling in this species likely occurs at stopover sites during migration and may also occur during migratory flights. This fly-and-forage strategy is used by other aerial foragers (e.g., Common Swift, Åkesson et al. 2012; Nathusius's bat, Šuba et al. 2012) allowing them to constantly refuel. It may also have the added benefit of allowing these species to undertake more direct migratory routes and consistent migratory bearings (like those seen in time-minimizing migrants) as they do not need to locate suitable stopover sites for refueling. Instead, these species forage on aerial insects that are presumably widely available throughout the region.

Male Bank Swallows had faster travel speeds than females. Sexbased differences in migratory timing have been attributed to faster refueling rates for males compared to females (Seewagen et al. 2013, Hays et al. 2018, but see Morbey et al. 2018). This result could be partly due to physiological differences between the sexes or differences in habitat selection at roost or stopover sites. Thus, if male Bank Swallows refuel more quickly than females, it could result in the faster travel speeds we observe. Alternatively, if the sexes select different weather conditions for migratory flights (Morganti et al. 2011), then we would also see sex-related differences in travel speeds. Such differences in travel speeds may also be driven by a need to reduce intraspecific competition during migration (Ellegren 1991, Jakubas and Wojczulanis-Jakubas 2010). We cannot rule out this possibility, although the lack of sexbased differences in departure dates (e.g., Jakubas and Wojczulanis-Jakubas 2010) suggests it is unlikely. Finally, observed differences in travel speed could represent a carry-over effect from the breeding season. If female body condition is lower than males after breeding, then females may require more frequent stopovers than males, reducing their migration pace.

Our work was limited by several factors. First, the array of Motus receiving stations in any given year of our study, and the range of these receivers $(\sim 15 \mathrm{~km})$, makes it difficult to determine movements for orientation and exploration of nearby areas if they were short $(<15 \mathrm{~km})$ or in a direction not covered by the network. This hampered our ability to confirm that initial migratory movements 
did not occur to the northwest of breeding colonies located in Tantramar River and our ability to detect individuals using inland migratory routes. Second, the battery life of tags deployed in 2014 and 2015 was shorter than those used in 2018, thus minimizing our inference about fall migration routes south of the northeastern USA.

\section{Conservation implications}

Bank Swallows are experiencing steep declines throughout their breeding range (Sauer et al. 2017). Conservation efforts to address these declines may include ensuring that there is suitable habitat during migration. Because this species does not appear to rely on specific sites for refuelling during migration (e.g., Gómez et al. 2017, Van Loon et al. 2017), we suggest that protection of migratory habitat should include a broad network of suitable habitats throughout their migratory range (Iverson et al. 1996, Mehlman et al. 2005, Poiani et al. 2006) as well as efforts to maintain ecological processes and habitats, coupled with anthropogenic land uses, within a landscape mosaic (Wiens 1994). Specifically, for Bank Swallows and other aerial foragers that use a fly-and-forage migration strategy, this includes management to provide broadly distributed foraging areas with an abundant or predictable supply of aerial insects. Properly managed, a habitat mosaic allows for the frequent foraging and variable stopover site use by this and other species of aerial foragers.

Responses to this article can be read online at: http://www.ace-eco.org/issues/responses.php/1463

\section{Acknowledgments:}

We thank the field assistants involved in tagging Bank Swallows during this study. Also, we thank the landowners that provided access to their properties, $P$. Thomas and B. Whittam at Environment and Climate Change Canada (ECCC) for their ongoing support, Bird Studies Canada for managing the Motus Wildlife Tracking System, and J. Bacon, D. Brinker, M. Deutschlander, Z. Dowlling, J. Eckler, A. Gonzalez, D. Hamilton, P. Loring, D. McNaughton, D. Mizrahi, L. Niles, K. O'Brien, J. Paquet, A. Patterson, N. Pau, R. Ronconi, J. Ruebesam, M. Seymour, A. Smith, H. Wheeler, and L. Ziemba for setting up and maintaining Motus receiving stations that detected Bank Swallows during this project. Funding for this project was provided by ECCC, and the New Brunswick Wildlife Trust Fund. Field protocols were approved by the Acadia University Animal Care Committee (\#06-18), Dalhousie Animal Ethics Committee (\#14-025), and ECCC (banding permit \#10619H).

\section{LITERATURE CITED}

Åkesson, S., R. Klaassen, J. Holmgren, J. W. Fox, and A. Hedenström. 2012. Migration routes and strategies in a highly aerial migrant, the Common Swift Apus apus, revealed by lightlevel geolocators. PLOS ONE 7:e41195. https://doi.org/10.1371/ journal.pone.0041195

Alerstam, T. 2009. Flight by night or day? Optimal daily timing of bird migration. Journal of Theoretical Biology 258:530-536. https://doi.org/10.1016/j.jtbi.2009.01.020
Alerstam, T. 2011. Optimal bird migration revisited. Journal of Ornithology 152:5-23. https://doi.org/10.1007/s10336-011-0694-1

Alerstam, T., and A. Hedenström. 1998. The development of bird migration theory. Journal of Avian Biology 29:343-369. https:// doi.org/10.2307/3677155

Barron, D. G., J. D. Brawn, and P. J. Weatherhead. 2010. Metaanalysis of transmitter effects on avian behaviour and ecology. Methods in Ecology and Evolution 1:180-187. https://doi. org/10.1111/j.2041-210X.2010.00013.x

Barton, K. 2016. MuMIn: multi-model inference. R package version 1.15.6.

Bates, D., M. Mächler, B. Bolker, and S. Walker. 2015. Fitting linear mixed-effects models using lme4. Journal of Statistical Software 67:1-48. https://doi.org/10.18637/jss.v067.i01

Bowman, J., M. C. Wallace, W. B. Ballard, J. H. Brunjes IV, M. S. Miller, and J. M. Hellman. 2002. Evaluation of two techniques for attaching radio transmitters to turkey poults. Journal of Field Ornithology 73:276-280. https://doi.org/10.1648/0273-8570-73.3.276

Brlík, V., J. Koleček, M. Burgess, S. Hahn, D. Humple, M. Krist, J. Ouwehand, E. L. Weiser, P. Adamík, J. A. Alves, D. Arlt, S. Barišić, D. Becker, E. J. Belda, V. Beran, C. Both, S. P. Bravo, M. Briedis, B. Chutný, D. Ćiković, N. W. Cooper, J. S. Costa, V. R. Cueto, T. Emmenegger, K. Fraser, O. Gilg, M. Guerrero, M. T. Hallworth, C. Hewson, F. Jiguet, J. A. Johnson, T. Kelly, D. Kishkinev, M. Leconte, T. Lislevand, S. Lisovski, C. López, K. P. McFarland, P. P. Marra, S. M. Matsuoka, P. Matyjasiak, C. M. Meier, B. Metzger, J. S. Monrós, R. Neumann, A. Newman, R. Norris, T. Pärt, V. Pavel, N. Perlut, M. Piha, J. Reneerkens, C. C. Rimmer, A. Roberto-Charron, C. Scandolara, N. Sokolova, M. Takenaka, D. Tolkmitt, H. van Oosten, A. H. J. Wellbrock, H. Wheeler, J. van der Winden, K. Witte, B. K. Woodworth, and Petr Procházka. 2020. Weak effects of geolocators on small birds: a meta-analysis controlled for phylogeny and publication bias. Journal of Applied Ecology 89:207-220. https://doi. org/10.1111/1365-2656.12962

Brown, J. M., and P. D. Taylor. 2015. Adult and hatch-year Blackpoll Warblers exhibit radically different regional-scale movements during post-fledging dispersal. Biology Letters 11:20150593. https://doi.org/10.1098/rsbl.2015.0593

Brzustowski, J., and D. Lepage. 2018. Motus: fetch and use data. $\mathrm{R}$ package version 1.0.0. [online] URL: http://motus.org

Costantini, D., and A. P. Møller. 2013. A meta-analysis of the effects of geolocator application on birds. Current Zoology 59:697-706. https://doi.org/10.1093/czoolo/59.6.697

Diemer, K. M., H. E. Wheeler, and J. J. Nocera. 2014. Retention rates of glue-attached radio-transmitters on two small bird species with contrasting life histories. Wilson Journal of Ornithology 126:39-46. https://doi.org/10.1676/13-098.1

Ellegren, H. 1991. Stopover ecology of autumn migrating Bluethroats Luscinia s. svecica in relation to age and sex. Ornis Scandinavica 22:340-348. https://doi.org/10.2307/3676506

Farmer, A. H., and J. A. Wiens. 1999. Models and reality: timeenergy trade-offs in Pectoral Sandpiper (Calidris melanotos) migration. Ecology 80:2566-2580. https://doi.org/10.2307/177241 
Gómez, C., N. J. Bayly, D. R. Norris, S. A. Mackenzie, K. V. Rosenberg, P. D. Taylor, K. A. Hobson, and C. D. Cadena. 2017. Fuel loads acquired at a stopover site influence the pace of intercontinental migration in a boreal songbird. Scientific Reports $7: 3405$.

Hays, Q. R., Y. E. Morbey, K. A. Hobson, J. E. Lyons, and C. G. Guglielmo. 2018. Effects of migration distance and sex on stopover timing and refueling by Wilson's Warblers. Journal of Field Ornithology 89:149-164. https://doi.org/10.1111/jofo.12246

Hedenström, A., and T. Alerstam. 1997. Optimum fuel loads in migratory birds: distinguishing between time and energy minimization. Journal of Theoretical Biology 189:227-234. https:// doi.org/10.1006/jtbi.1997.0505

Hijmans, R. J. 2018. geosphere: Spherical trigonometry. R package version 1.5-7.

Imlay, T. L., K. A. Hobson, A. Roberto-Charron, and M. L. Leonard. 2018. Wintering areas, migratory connectivity and habitat fidelity of three declining Nearctic-Neotropical migrant swallows. Animal Migration 5:1-16. https://doi.org/10.1515/ ami-2018-0001

Imlay, T. L., and P. D. Taylor. In press. Diurnal and crepuscular activity during migration for four species of aerial foragers. Wilson's Journal of Ornithology.

Iverson, G. C., S. E. Warnock, R. W. Butler, M. A. Bishop, and N. Warnock. 1996. Spring migration of Western Sandpipers along the Pacific Coast of North America: a telemetry study. Condor 98:10-21. https://doi.org/10.2307/1369502

Jakubas, D., and K. Wojczulanis-Jakubas. 2010. Sex-and agerelated differences in the timing and body condition of migrating Reed Warblers Acrocephalus scirpaceus and Sedge Warblers Acrocephalus schoenobaenus. Naturwissenschaften 97:505-511. https://doi.org/10.1007/s00114-010-0666-y

Johnson, G. D., J. L. Pebworth, and H. O. Krueger. 1991. Retention of transmitters attached to passerines using a glue-on technique. Journal of Field Ornithology 62:486-491.

Kuznetsova, A., P. B. Brockhoff, and R. H. B. Christensen. 2017. lmerTest package: tests in linear mixed effects models. Journal of Statistical Software 82:1-26. https://doi.org/10.18637/jss.v082. i13

Kvist, A., Å. Lindström, M. Green, T. Piersma, and G. H. Visser. 2001. Carrying large fuel loads during sustained bird flight is cheaper than expected. Nature 413:730-732. https://doi. org/10.1038/35099556

McKinnon, E. A., C. M. Macdonald, H. G. Gilchrist, and O. P. Love. 2016. Spring and fall migration phenology of an Arcticbreeding passerine. Journal of Ornithology 157:681-693. https:// doi.org/10.1007/s10336-016-1333-7

Mehlman, D. W., S. E. Mabey, D. N. Ewert, C. Duncan, B. Abel, D. Cimprich, R. D. Sutter, and M. Woodrey. 2005. Conserving stopover sites for forest-dwelling migratory landbirds. Auk 122:1281-1290. https://doi.org/10.1093/auk/122.4.1281

Miller, T. A., R. P. Brooks, M. J. Lanzone, D. Brandes, J. Cooper, J. A. Tremblay, J. Wilhelm, A. Duerr, and T. E. Katzner. 2016.
Limitations and mechanisms influencing the migratory performance of soaring birds. Ibis 158:116-134. https://doi. org/10.1111/ibi.12331

Mitchell, G. W., B. K. Woodworth, P. D. Taylor, and D. R. Norris. 2015. Automated telemetry reveals age specific differences in flight duration and speed are driven by wind conditions in a migratory songbird. Movement Ecology 3:19. https://doi. org/10.1186/s40462-015-0046-5

Mong, T. W., and B. K. Sandercock. 2007. Optimizing radio retention and minimizing radio impacts in a field study of Upland Sandpipers. Journal of Wildlife Management 71:971-980. https:// doi.org/10.2193/2005-775

Morbey, Y. E., C. G. Guglielmo, P. D. Taylor, I. Maggini, J. Deakin, S. A. Mackenzie, J. M. Brown, and L. Zhao. 2018. Evaluation of sex differences in the stopover behavior and postdeparture movements of wood-warblers. Behavioral Ecology 29:117-127. https://doi.org/10.1093/beheco/arx123

Morganti, M., U. Mellone, G. Bogliani, N. Saino, A. Ferri, F. Spina, and D. Rubolini. 2011. Flexible tuning of departure decisions in response to weather in Black Redstarts Phoenicurus ochruros migrating across the Mediterranean Sea. Journal of Avian Biology 42:323-334. https://doi.org/10.1111/j.1600-048X.2011.05331. $\mathrm{X}$

Morganti, M., D. Rubolini, S. Åkesson, A. Bermejo, J. de la Puente, R. Lardelli, F. Liechti, G. Boano, E. Tomassetto, M. Ferri, M. Caffi, N. Saino, and R. Ambrosini. 2018. Effect of light-level geolocators on apparent survival of two highly aerial swift species. Journal of Avian Biology 49:jav-01521. https://doi.org/10.1111/ jav.01521

Nilsson, C., J. Bäckman, and T. Alerstam. 2014. Seasonal modulation of flight speed among nocturnal passerine migrants: differences between short- and long-distance migrants. Behavioral Ecology and Sociobiology 68:1799-1807. https://doi.org/10.1007/ s00265-014-1789-5

Nilsson, C., R. H. G. Klaassen, and T. Alerstam. 2013. Differences in speed and duration of bird migration between spring and autumn. American Naturalist 181:837-845. https://doi.org/10.1086/670335

Poiani, K. A., B. D. Richter, M. G. Anderson, and H. E. Richter. 2006. Biodiversity conservation at multiple scales: functional sites, landscapes, and networks. BioScience 50:133-146. https:// doi.org/10.1641/0006-3568(2000)050[0133:BCAMSF]2.3.CO;2

R Core Team. 2018. R: A language and environment for statistical computing. R Foundation for Statistical Computing, Vienna, Austria.

Raim, A. 1978. A radio transmitter attachment for small passerine birds. Bird-Banding 49:326-332. https://doi.org/10.2307/4512391

Rappole, J. H., and A. R. Tipton. 1991. New harness design for attachment of radio transmitters to small passerines. Journal of Field Ornithology 62:335-337.

Saldanha, S. 2016. Foraging and roosting habitat use of nesting Bank Swallows in Sackville, NB. Thesis. Dalhousie University, Halifax, Nova Scotia, Canada.

Sauer, J. R., D. K. Niven, J. E. Hines, D. J. Ziolkowski Jr, K. L. Pardieck, J. E. Fallon, and W. A. Link. 2017. The North American 
Breeding Bird Survey, results and analysis 1966-2015. Version 2.07.2017. USGS Patuxent Wildlife Research Center, Laurel, Maryland, USA.

Seewagen, C. L., C. G. Guglielmo, and Y. E. Morbey. 2013. Stopover refueling rate underlies protandry and seasonal variation in migration timing of songbirds. Behavioral Ecology 24:634-642. https://doi.org/10.1093/beheco/ars225

Smetzer, J. R., and D. I. King. 2018. Prolonged stopover and consequences of migratory strategy on local-scale movements within a regional songbird staging area. Auk 135:547-560. https:// doi.org/10.1642/AUK-18-4.1

Smetzer, J. R., D. I. King, and P. D. Taylor. 2017. Fall migratory departure decisions and routes of Blackpoll Warblers Setophaga striata and Red-eyed Vireos Vireo olivaceus at a coastal barrier in the Gulf of Maine. Journal of Avian Biology 48:1451-1461. https:// doi.org/10.1111/jav.01450

Strandberg, R., and T. Alerstam. 2007. The strategy of fly-andforage migration, illustrated for the Osprey (Pandion haliaetus). Behavioral Ecology and Sociobiology 61:1865-1875. https://doi. org/10.1007/s00265-007-0426-y

Strandberg, R., R. H. G. Klaassen, P. Olofsson, and T. Alerstam. 2009. Daily travel schedules of adult Eurasian Hobbies Falco subbuteo - variability in flight hours and migration speed along the route. Ardea 97:287-295. https://doi.org/10.5253/078.097.0304

Streby, H. M., J. M. Refsnider, and D. E. Andersen. 2014. Redefining reproductive success in songbirds: moving beyond the nest success paradigm. Auk 131:718-726. https://doi.org/10.1642/ AUK-14-69.1

Šuba, J., G. Petersons, and J. Rydell. 2012. Fly-and-forage strategy in the bat Pipistrellus nathusii during autumn migration. Acta Chiropterologica 14:379-385. https://doi.org/10.3161/150811012x661693

Sykes Jr, P. W. J., J. W. Carpenter, S. Holzman, and P. H. Geissler. 1990. Evaluation of three miniature radio transmitter attachment methods for small passerines. Wildlife Society Bulletin 18:41-48.

Taylor, P. D., T. L. Crewe, S. A. Mackenzie, D. Lepage, Y. Aubry, Z. Crysler, G. Finney, C. M. Francis, C. G. Guglielmo, D. J. Hamilton, R. L. Holberton, P. H. Loring, G. W. Mitchell, D. Norris, J. Paquet, R. A. Ronconi, J. Smetzer, P. A. Smith, L. J. Welch, and B. K. Woodworth. 2017. The Motus Wildlife Tracking System: a collaborative research network to enhance the understanding of wildlife movement. Avian Conservation and Ecology 12(1):8. https://doi.org/10.5751/ACE-00953-120108

Turner, A. 2004. Family Hirundinidae (swallows and martins). Pages 602-685 in J. Del Hoyo, A. Elliott, and D. Christie, editors. Handbook of the birds of the world. Volume 9. Cotingas to pipits and wagtails. Lynx Edicions, Barcelona, Spain.
Van Loon, A., J. D. Ray, A. Savage, J. Mejeur, L. Moscar, M. Pearson, M. Pearman, G. T. Hvenegaard, N. Mickle, K. Applegate, and K. C. Fraser. 2017. Migratory stopover timing is predicted by breeding latitude, not habitat quality, in a longdistance migratory songbird. Journal of Ornithology 158:745752. https://doi.org/10.1007/s10336-017-1435-x

Vincenty, T. 1975. Direct and inverse solutions of geodesics on the ellipsoid with application of nested equations. Survey Review 23:88-93. https://doi.org/10.1179/sre.1975.23.176.88

Ward, M. P., and A. Raim. 2011. The fly-and-social foraging hypothesis for diurnal migration: why American Crows migrate during the day. Behavioral Ecology and Sociobiology 65:1411-1418. https://doi.org/10.1007/s00265-011-1151-0

Warnock, N., J. Y. Takekawa, and M. A. Bishop. 2004. Migration and stopover strategies of individual Dunlin along the Pacific coast of North America. Canadian Journal of Zoology 82:1687-1697. https://doi.org/10.1139/z04-154

Wiens, J. A. 1994. Habitat fragmentation: island v landscale perspectives on birg conservation. Ibis 137:S97-S104. https://doi. org/10.1111/j.1474-919X.1995.tb08464.X

Winger, B. M., G. G. Auteri, T. M. Pegan, and B. C. Weeks. 2019. A long winter for the Red Queen: rethinking the evolution of seasonal migration. Biological Reviews 94:737-752. https://doi. org/10.1111/brv. 12476

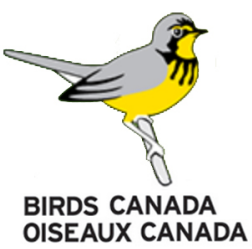


Appendix 1. Supplementary material on the locations of Motus Wildife Tracking System receiving stations and the fall migratory movements of Bank Swallow tracked in 2014, 2015 or 2018 from New Brunswick, Canada.
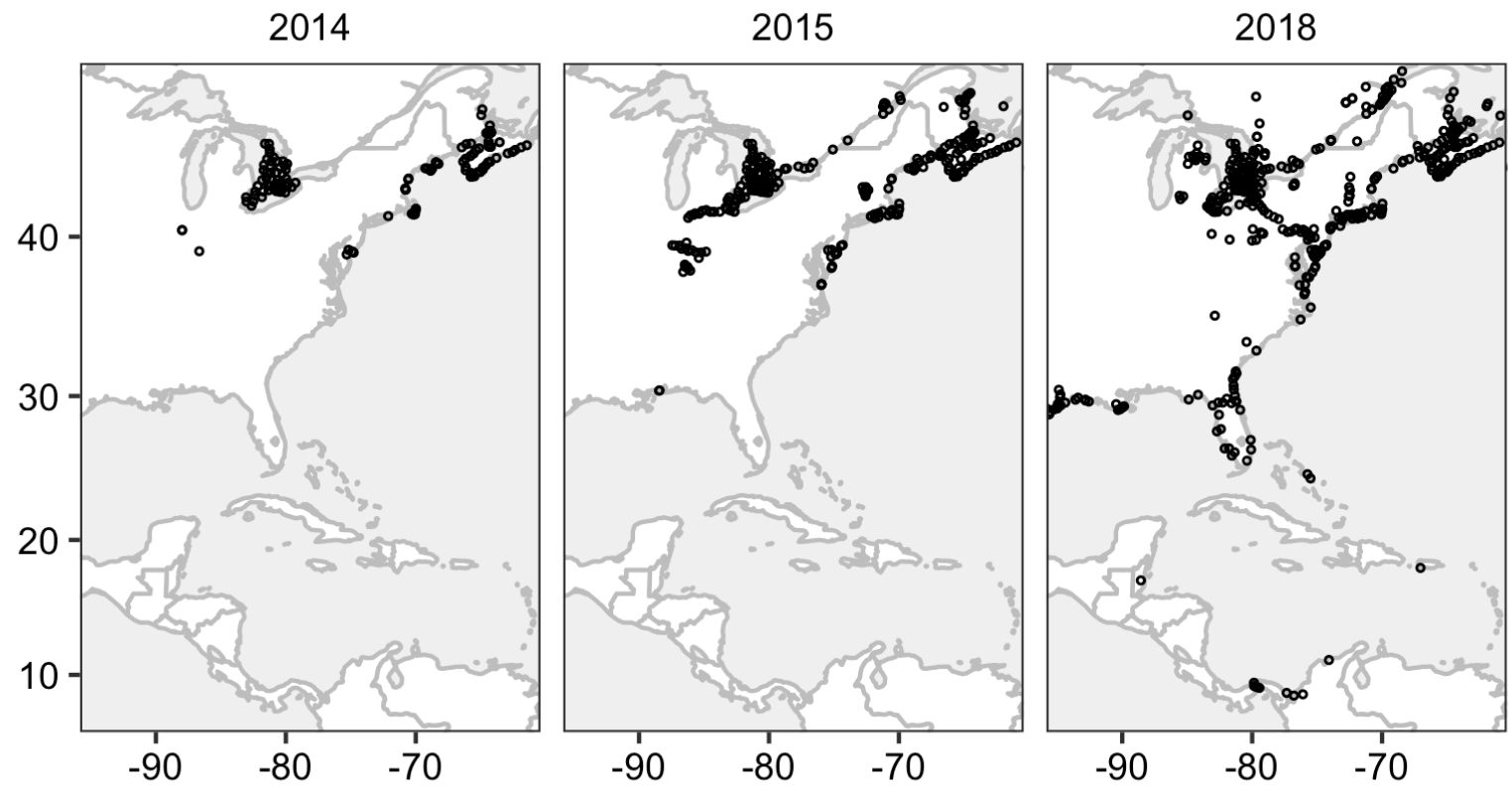

Fig. A1.1. Locations of Motus Wildlife Tracking System receiving stations throughout North and Central America during each year of this study. 

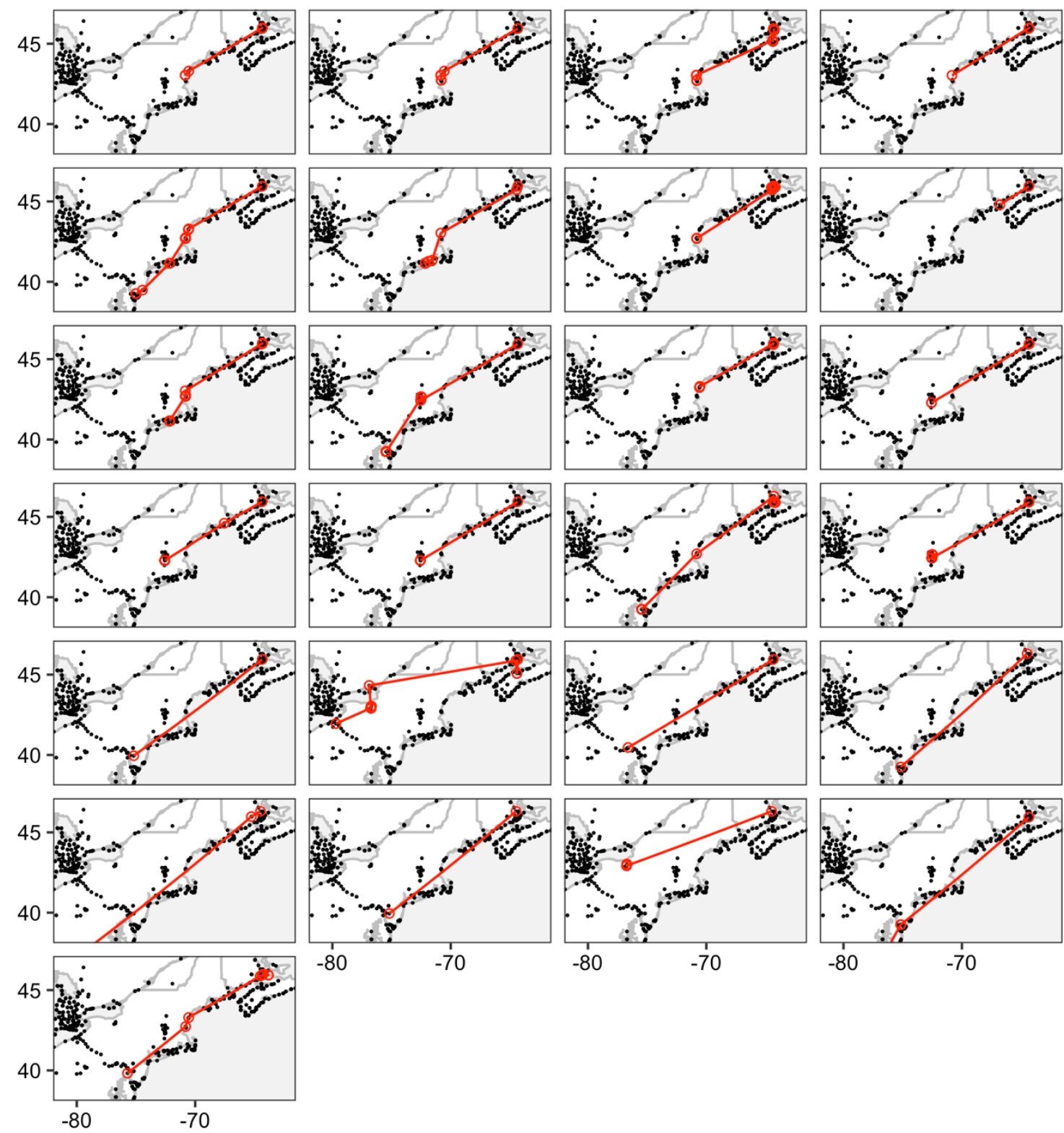

$-80$

Fig. A1.2. Fall migratory movements of 25 Bank Swallows throughout northeastern North America. The individuals shown were detected at a minimum of 1 Motus receiving station located at least $100 \mathrm{~km}$ away from their breeding colonies. 